\title{
Methodological support to establish a collaborative non-hierarchical business network for complex product manufacturing
}

\author{
A.H.M. Shamsuzzoha* and Timo Kankaanpää \\ Department of Production, \\ University of Vaasa, \\ P.O. Box 700, FI-65101, Finland \\ Fax: +358-6-324-8467 \\ E-mail: ahsh@uwasa.fi \\ E-mail: tka@uwasa.fi \\ *Corresponding author

\section{Luis Carneiro and Ricardo Almeida} \\ INESC Porto, \\ Rua do Campo Alegre, 687, \\ 4150-179 Porto, Portugal \\ E-mail: luis.carneiro@inescporto.pt \\ E-mail: ralmeida@inescporto.pt
}

\begin{abstract}
Increasing demand on dynamic business network motivates manufacturing companies, especially small and medium sized enterprises (SMEs) to be collaborative for achieving potential market gains. This need can be fulfilled by forming non-hierarchical business network, where the partners integrate with each other after identifying specific business opportunity. This research focuses to demonstrate the methodological stages of enabling a virtual organisation within the European RTD project Net-Challenge. In this research, methodological support to identify and collect the business scenarios and basic requirements related with choosing appropriate partners, building trust and sharing valuable information among them are presented. The fundamental issues related to collaboration such as critical factors for partnerships, criteria for qualifying a potential partner, assessment of a partner are elaborated within the scope of this paper. The paper is concluded with presenting an empirical study of six case companies and the issues related to business collaboration are critically discussed.
\end{abstract}

Keywords: business collaboration; small and medium sized enterprises; SMEs; non-hierarchical network; methodology; business scenario; case companies.

Reference to this paper should be made as follows: Shamsuzzoha, A.H.M., Kankaanpää, T., Carneiro, L. and Almeida, R. (2012) 'Methodological support to establish a collaborative non-hierarchical business network for complex product manufacturing', Int. J. Networking and Virtual Organisations, Vol. 11, Nos. 3/4, pp.363-381.

Biographical notes: A.H.M. Shamsuzzoha is a Post-Doctoral Researcher in the Department of Production, University of Vaasa, Finland, since September 2011. He received his $\mathrm{PhD}$ in Industrial Management from the University of 
Vaasa, Finland in 2010 and his Master of Science in Mechanical Engineering from the University of Strathclyde, Glasgow, UK. Currently, his research activities are devoted to the integration of business partners through virtual enterprises and logistics management in product development. His major research interest lies in the area of mass customisation, business collaboration, supply chain management and logistics networks. He has published several research papers both in international journals and conference proceedings.

Timo Kankaanpää is a Manager at Technobothnia Research Centre, jointly organised by University of Vaasa, Vaasa University of Applied Sciences and Novia University of Applied Sciences, Vaasa, Finland since 2010. He received his Licentiate degree from University of Vaasa in 1999. Previously, he worked as a Principal Lecturer and Dean at the Vaasa University of Applied Sciences, Finland from 1997 to 2010. Currently, he is a Manager of Technobothnia Research Centre. His responsibility is mainly focused to develop virtual factories in the field of sustainable business and renewable energy solutions for the industrial establishments. His research activities are devoted to the integration of business collaboration with especial focus on ICT-based solution approach. He has published several research papers both in international journals and conference proceedings.

Luis Maia Carneiro is an Operational Manager of the Manufacturing Systems Engineering Unit of INESC Porto, since 1996. He completed his degree in Electrical Engineering from the Faculty of Engineering, University of Porto, Portugal (1987) and Master in Business and Administration (MBA) by the University of Porto (1993). During the past 20 years, he has participated in many national and European RTD projects, often with leading roles. He was the Coordinator of the European RTD projects Net-Challenge (innovative networks of SMEs for complex products manufacturing) and MEDIAT-SME (methodology and tools for world-best introduction of innovative market mediation systems and services in traditional SMEs) and was the Director of the national project RCED - High Performance Collaborative Enterprise Networks. His key research interests include collaborative networks and innovation management.

Ricardo Almeida is a PhD student from MIT Portugal Doctoral Program in the engineering design and advanced manufacturing area. Currently, he is a researcher at INESC Porto and also the Director of Computer Engineering's course and Master Programme on Software Engineering and Information Systems of Universidade Lusofona do Porto. For nine years, he was a Software Development Director on a Portuguese ERP system for production management, implemented in Portugal and Spain. His main R\&D interests are in the domain of information technologies for business collaborative networks and software engineering.

\section{Introduction}

It is nowadays a growing concern for industries especially for small and medium enterprises (SMEs) to be networked or collaborated with a view to achieve higher competitive advantages, which is usually not possible when they are in isolated form each other. In manufacturing industries, collaboration provides key market demands through sharing experiences, competencies and resources (Singh and Mitchell, 1996; Robson and Bennett, 2000). In recent years, due to the advancements of ICT tools, increasing 
demands for information exchange and market needs, pushing manufacturing firms to focus for breeding collaboration within their business community. Business community, which can be defined as a business environment where many firms especially SMEs are collaborated based on trust and communication mechanism. This community can be small grouping of companies (up to 10 or 20 companies) to a larger number of companies even several hundred (Almeida et al., 2010).

In today's manufacturing firms there exist various forms of collaborations such as; buyer-sellers, virtual enterprises, collaborative virtual laboratory, virtual communities, etc. (Camarinha-Matos and Afsarmanesh, 2007). These different types of collaborations are evolved not only for business survivals but also for achieving higher market share within unstable business environments. Industrial sectors especially for (SMEs), the involvement in a collaborative network enhances the management of their product development processes through resource sharing, dynamism in internal operations and reengineering production processes. If this collaboration is properly managed, it can provide a basis for competiveness, world-excellence and agility in turbulent market environments and can support SMEs in identifying and exploiting new business potential, boost innovation and increase their knowledge (Welty and Becerra-Fernandez, 2001; Camarinha-Matos et al., 2008).

Business community can be collaborated in terms of both hierarchical and nonhierarchical structure depending on the objectives, requirements and the controlling power of collaborating firms on each other. There exists clearly described structure in hierarchical collaboration, where the collaborations are goal-oriented and define clear roles for its participants. This type of structure is usually exerts tighter controlling power over its business partners and generally occurred between larger firms and smaller ones. On the other hand, in non-hierarchical collaboration firms are more loosely structured in nature, where the leaderships are equally shared among partners and exists a common goal of success as a 'whole' rather than the individual firms. Generally, small and medium size firms are collaborated hierarchically with larger firms, whereas they collaborate non-hierarchically with each others. In this research, we have considered nonhierarchical collaborations among SMEs, where the objectives are to achieve the benefits from economics of size, competitive advantage, and flexibility in production and to focus on totally different market segments than their competitors.

Before moving for any sorts of collaboration among business community, there needs up-to-date information management's tools or methodologies with a view to exchange valuable information among the collaborative partners. This information exchange extends the operating environment; achieve common or compatible goals and interactions among the SMEs in collaborative networks (Webster, 1995; Levy et al., 2003). It is very much essential for SMEs which are especially producing low volume and high variety complex products. Complex products can be termed as products which are highly custom-built or individually tailored and designed products such as textiles or fabrics, shoes, electronics etc. These types of products are usually more than mass customisation level and comparatively unstable, where the consumption rates or demands are varied from regions to regions or even seasons to seasons. The SMEs that are producing fairly complex products are networked on the basis of resource availability, time-to-market and minimising developmental risks.

The rest of the paper is organised as follows: Section 2 presents the review of the existing literature on business collaboration, while Section 3 states the brief explanation of Net-Challenge project and methodology. Section 4 illustrates the overall research 
methodology on this study. In Section 5, the prospective business scenarios of the six case companies and their interconnectivity are presented, whereas, Section 6 outlines the descriptions of business partners and non-hierarchical collaboration in terms of critical success factors for partnerships, criterion for qualify a partner, assessment of a business partner. Section 7 presents the empirical study, where the fundamental descriptions of the case industries are highlighted. The basic outcomes from this research are discussed and concluded in Section 8.

\section{Theoretical study about collaboration}

The term collaboration simply could be defined as 'working together'. Bititci et al. (2004) provides a more formal definition of collaboration as "a number of autonomous organisations working together, pooling and sharing resources, information, systems and risk for mutual benefit". In such context, collaborative SMEs are not only depending on supply chain network but also network in technology development (technology chain) and product development (design chain). The concepts of collaborations among SMEs are beyond the supply chain and strategic alliances, where each firms try to maximise their own performance through shared goals and optimised gains among partnering firms. In this approach, the selection of partnering organisations and measuring their performances are very much crucial for successful business competence.

With a view for selecting appropriate collaborating partners, SMEs face a number of challenges to successfully working with them and for achieving a common goal. A partnership is usually built on sharing expertise or knowledge and trust in a B2B inter-organisational environment to be innovative and reducing costs (Jones and Bowie, 1998). Partners or collaborators competence is another element of trust and business community also need to be convinced of a potential partner's technical knowledge, skills and credibility, resources, capacities etc. before embracing collaboration (Ratnasingam, 2001). After selecting potential partners based on various criterions next critical step is to evaluate those partners on a regular basis to measure the performance and credibility for continuing the collaboration. The following subsections are discussed the requirements for qualifying and assessing of business partners in general.

Usually, small firms have specialised in a very narrow business area which has limitations to compete in the market, while large firms use their supply networks as resource pools to be benefited. During current economic recession it is very difficult for SMEs to maintain higher productivity, whereas large firms will utilise the flexibility of their suppliers' instead of reducing their own production. To survive such challenging situation SMEs should be ready to build non-hierarchical cooperation and collaboration themselves to win markets in order to survive. The growing rate of networking among SMEs reflects a catch-up of technology that considers as one of the competitive advantages. Indeed, the very success of the collaboration among SMEs may be due to their ability to utilise external networks more efficiently (Nooteboom, 1994; Rothwell and Dodgson, 1994). In a broader scope SMEs have overcome barriers to growth due to absolute limits to resources by the astute use of collaboration (Ahern, 1993; Narula, 2004; Van Dijk et al., 1997).

Mytelka (1991) states that a firm's competitiveness may be in fact determined more by its external network than its size. When there is more collaboration among SMEs, they overcome their economic of size and find the proper market niche even on complex 
product with low volume and high variety. Those products are frequently defined as engineer-to-order (ETO) products and the manufacturing of such products is basically project-based. These products are highly customer-oriented and individually tailored according to customer's own preferences and choices. To cope up such challenges in product development, firms adopt external support in a non-hierarchical fashion to exchange valuable information and resources between each others to fulfil market demands and earn more revenue. Isolation nowadays kills firms, especially for SMEs which affects negatively over them in terms of innovation and prosperity.

\section{The Net-Challenge project}

Due to the current unexpected demand, European SMEs have to adopt new business models and to establish dynamic and non-hierarchical networks to respond to market opportunities, assuring quick response, fast time to market, differentiated offerings and competitive prices. Sustainability for SMEs will be found in high-variety low-volume businesses, related with complex products manufacturing. However, there are currently no proven, effective methodologies, approaches or tools to support SMEs in creating, managing and dissolving this type of dynamic and non-hierarchical networks.

Net-Challenge is a European research project in the area of collaborative business networks, which aims the development of new concepts and tools to support SMEs on the creation and efficiently operating of non-hierarchical collaborative business networks, enabling and improving significantly their competitive position, processes and ICT decision support tools.

\subsection{Net-Challenge methodology}

The Net-Challenge project provides a Methodology for European SMEs in order to interact with each other through collaborative activities. The high level stages within the Net-Challenge methodology can be displayed as in Figure 1. In Build phase of the Methodology, the business community is developed through continuous knowledge sharing and standardises and improves communication with the potential partners after qualifying them with predefined criterions. The second phase Form, where the qualified partners are selected with the objective to form the virtual organisation after identifying the potential business opportunity. At this stage the required lead-time to develop a product or service is calculated in order to prepare a quotation for the prospective customer.

Figure 1 Net-Challenge methodology for creating a virtual organisation
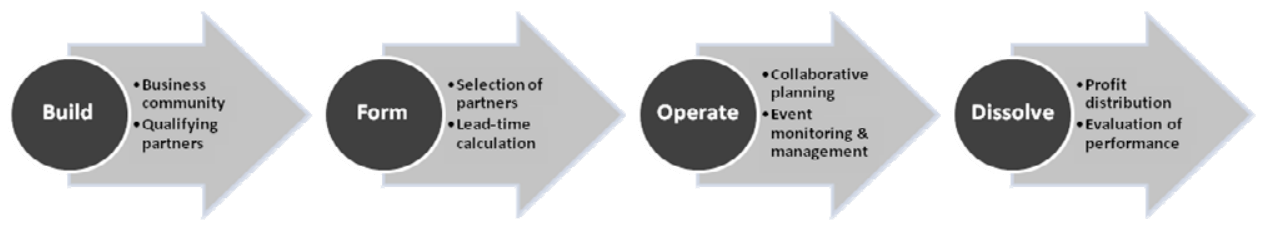

In Operate, the third phase of the Methodology provides necessary support to develop the product in terms of creating collaborative planning and scheduling among partners. In this phase, production statuses are updated on real-time environment and any 
abnormalities within the operational processes (events) are monitored and managed. The final phase Dissolve responsible for dissolution of the previous formed virtual organisation after successfully achieved the identified business opportunity. At this phase, the essential profits are distributed among the partners and the overall performance of the virtual organisation is evaluated and the outcomes are stored for future reference.

\section{Research methodology}

The methodology used for this study was based, initially, on a research for current trends related with business processes for production and collaboration between companies; aiming the development of a template questionnaire that could be used when interviewing companies, by all partners from Net-Challenge project.

The study was conducted through multiple case study approach, gathering and comparing retrieved information (discussed on personal meetings and Skype sessions, between researchers and business partners) and sharing the initial findings of the case companies. Therefore, it has been identified three internal stages:

- definition (creation of templates to be used on interviews and questionnaires)

- activities (activities and tasks performed to achieve the desired findings)

- deliverables (documents produced, 'internally', by researchers and business partners).

Figure 2 presents the three internal stages described previously, identifying the created templates, their major activities and interactions between partners (interviews, meetings, etc), and developed documents.

Figure 2 Timeline of the research activities (see online version for colours)
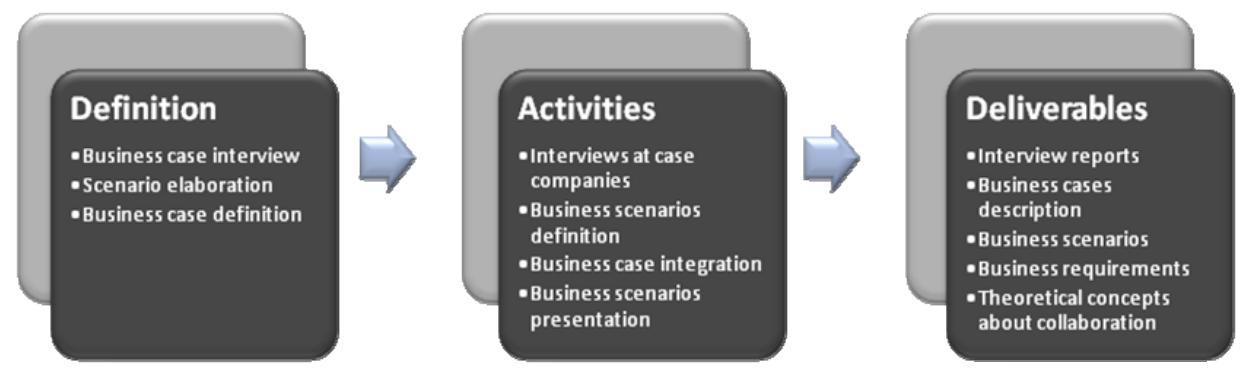

\subsection{Definition stage}

The definition stage included the creation of data templates and questionnaires' definition, for a complete information acquisition. For instance, the business case interview questionnaire template considered the following subjects (for each case company): background information (market targets, products); current major production processes and supply-chain strategies; current status and practices for collaboration and networking; Future needs for collaboration and respective support tools. Figure 3 presents the workflow document defined for the questionnaire, which was used as guideline on the interviews. 
Figure 3 Workflow for business case interview questionnaire template (see online version for colours)

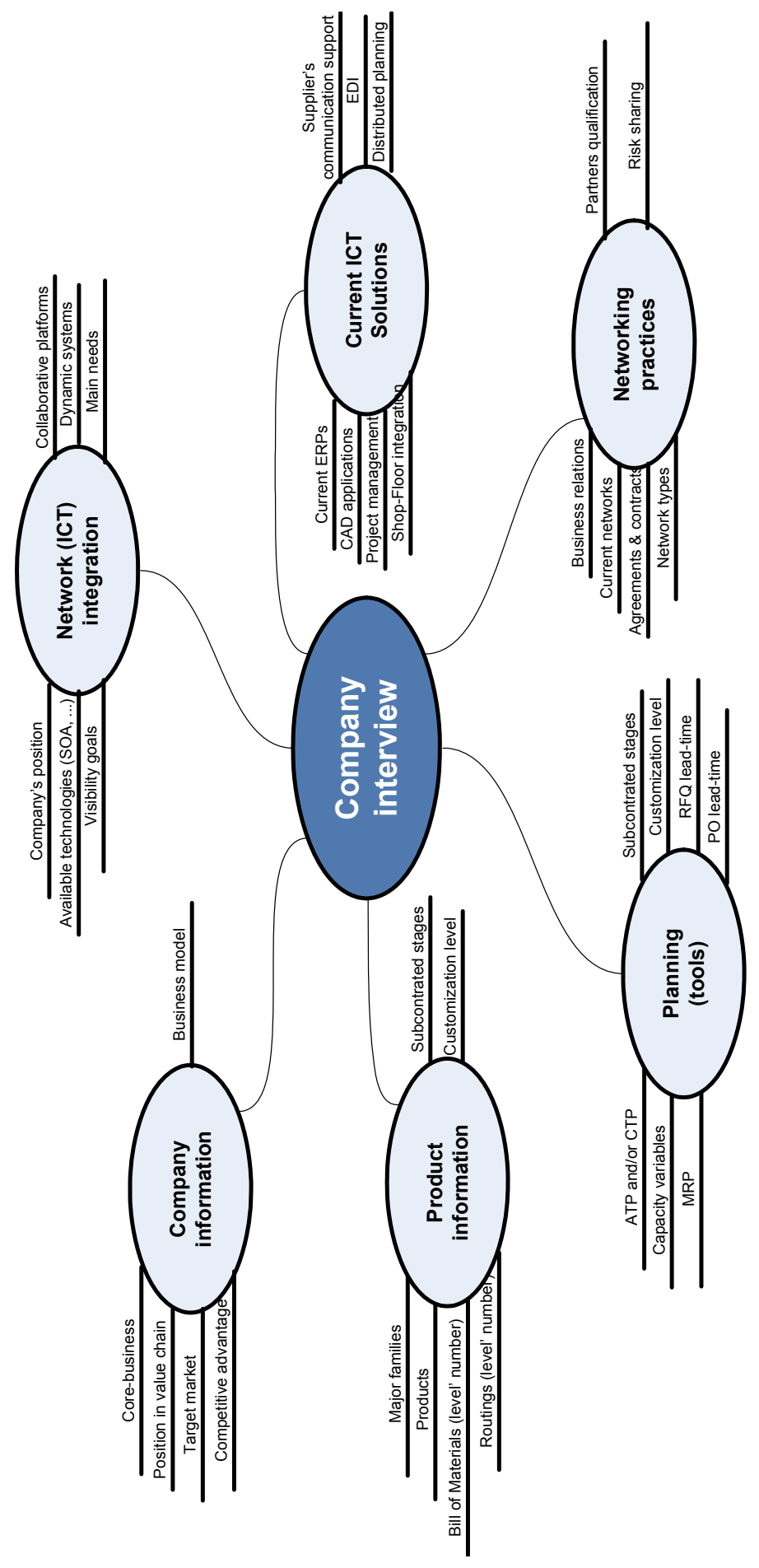




\subsection{Activities stage}

The Activities stage included all the procedures performed to obtain important information and validation activities, such as personal meetings and Skype sessions between researchers and partners. The last activity (research) has gathered additional knowledge from similar research projects, concerning the real business implementation, which was one of the major concerns of Net-Challenge project. This stage has followed an innovative approach, regarding business processes' abstraction. It began with a business case description, which included (as Net-Challenge business partners) six companies:

- two Portuguese company (from textile and apparel industries)

- two Italian companies (from shoe industry)

- two Spanish companies (from electro-extrusion machines and robotics industries).

All the business cases represent very traditional industries in their area and the market share of each industry sector extremely important for their home country. Each business case includes companies that are representative examples of thousands of similar companies acting in the same market and are key members of larger business networks.

This deliverable assumed a very important role since permitted all partners to a concrete evaluation of companies' business needs and expectations. The following step was, firstly, conducted by researchers; searching and developing possible scenarios that could raise companies' needs and to promote competitive advantage; this lead to the creation of business scenarios, which act like 'short stories', easily to understand and discuss with companies for a complete validation. After this stage, research partners resumed the common scenarios between all companies (defined as crucial and which will be presented on this study, on the next chapters).

After refined the scenarios' conclusions, some important concepts have been raised from companies' meetings, like the need to enhance the concept of collaboration. This study focuses, exclusively, on the creation of business communities to promote collaboration between companies. Finally, the definition of business requirements was performed and promoted their classification, in order to prioritise its development on the Net-Challenge project.

\subsection{Deliverables stage}

This stage resumes the development of the required documentation for Net-Challenge project. It has been used some collaborative tools (like Google Wave and Google Documents) on the development of these documents, which acted like a collaborative 'exercise', for a better understand of the needs and behaviours.

These three phases were assumed on an iterative approach, been performed for several times, until reach a consistent result. As major results, it has been created the deliverables: business cases, business scenario, presented further.

\section{Business scenarios}

In order to cope with business scenario, firms need to focus on activities that create higher value of their products. For that, firms must pursue product and service 
innovation, offer higher value products and service, maximise the extent of their value chains decision related to production and delivery. In any scenario cost reduction across the entire value chain is necessary. To achieve such objectives, firms need to initiate collaboration which will allow them to target large markets without the need to invest heavily in facilities, machineries and human resources. This will allow flexible adaptation to market changes and as a consequence the reduction of risk. The networking with a large number of specialised firms will allow the development of more innovative products.

Before formulating specific business scenarios, firms have to identify the most valuable and important scenarios and prioritise them for implementation. It needs to examine the multiple scenario approach as an important corporate innovation in strategic planning. It is also needed to analyse how scenario planning tries to meet certain methodological, organisational and psychological challenges facing today's senior managers (Schoemaker, 1993). Both benefits and obstacles to implementing business scenario in organisations are required to be identified. Three major disciplines that use business scenarios are strategic management, human-computer interaction and software and systems engineering with a view to deal with description of current and future realities (Jarke et al., 1998).

Table 1 Generic business scenarios of the six case companies

\begin{tabular}{llc}
\hline $\begin{array}{l}\text { Scenario } \\
\text { number }(S N)\end{array}$ & Description of the scenario & $\begin{array}{c}\text { Networking } \\
\text { phase }\end{array}$ \\
\hline SN1 & A company wants to participate in a business community & Build \\
SN2 & $\begin{array}{l}\text { A community member invites a company to participate in the } \\
\text { business community }\end{array}$ & Build \\
SN3 & Selection of potential partners for a new business line & \\
SN4 & Knowledge sharing within the network & Build \\
SN5 & Qualification of potential partners for a new business line & Build \\
SN6 & Select partners for a specific market opportunity & Qualify \\
SN7 & Design a new collection (catalogue) & Qualify \\
SN8 & Developing market research & Form \\
SN9 & Standardise communication with customers & Form \\
SN10 & All processes of the company are concentrated in one and only & Form \\
& very simple ICT tool & Form \\
SN11 & Improve operations plan for an order & \\
SN12 & Monitoring operations & Operate \\
SN13 & Reaction to an unexpected event & Operate \\
SN14 & Evaluating the network performance & Operate \\
SN15 & Adjusting production capacity to meet expected demand & Operate \\
SN16 & Creating a global production schedule for an order & Operate \\
SN17 & Subcontracting & Operate \\
SN18 & Network dissolution & Operate \\
\hline & & Dissolve \\
\hline
\end{tabular}

In this research, six case companies were studied in order to accommodate generic business scenarios, which are displayed in Table 1. The first five scenarios support to the establishment of the business community (virtual breeding environment), including more 
companies into the community, browsing and the qualification of the partners. Scenario number 5 and 6 imply for qualifying and selecting qualified potential partners, while scenario number $7,8,9$, and 10 responsible for forming a virtual organisation. The operational phase of a particular virtual organisation defines by the scenario number 11 , $12,13,14,15,16$ and 17 . The final dissolution phase of the virtual organisation is expressed by the scenario number 18 .

Figure 4 The relationship among defined business scenarios of the six case companies (see online version for colours)

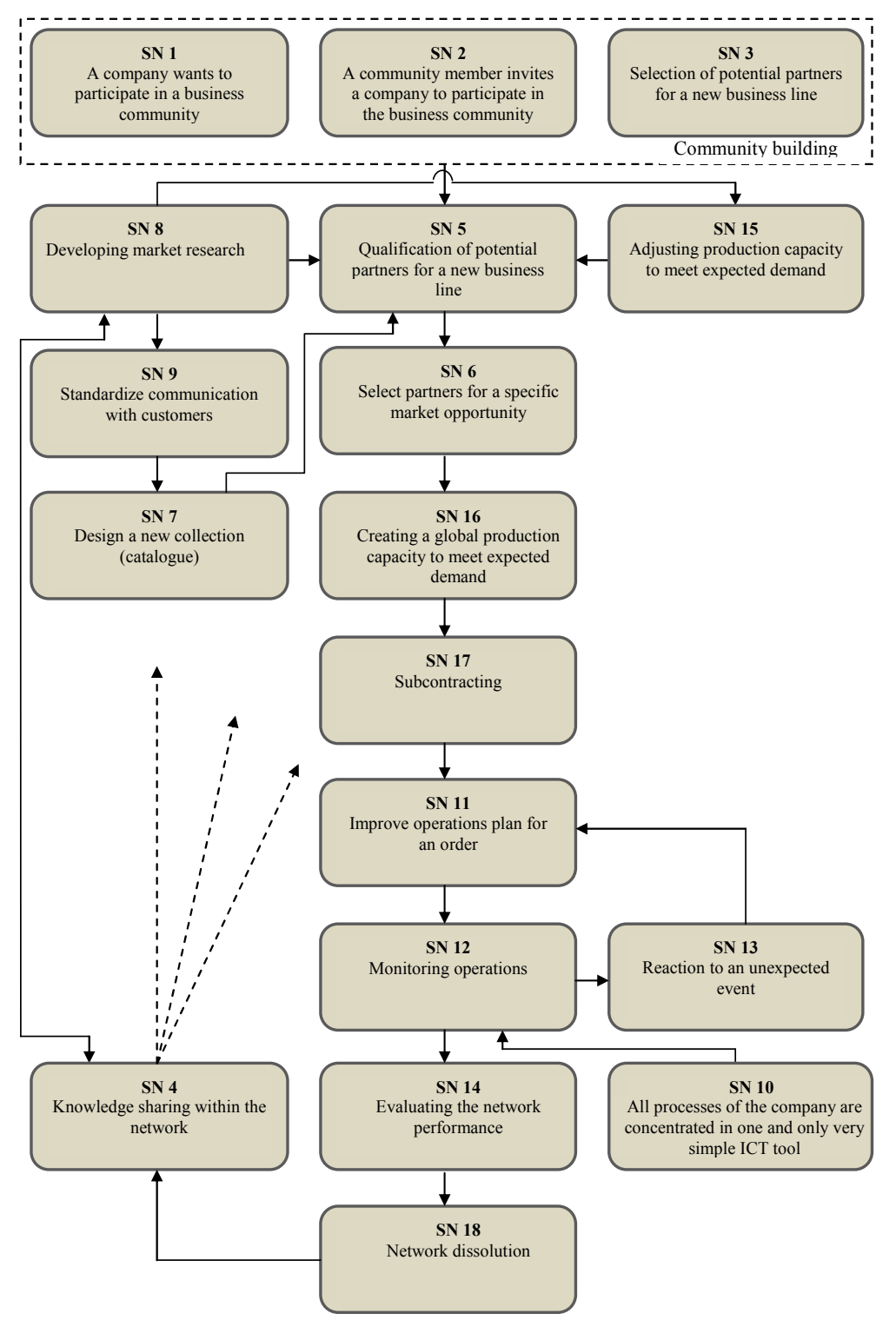

There needs a strong commitment and trust among business partners to fulfil various scenarios which are beneficial to fulfil their business targets. The interdependencies 
among major business scenarios can be seen in Figure 4. From Figure 4, it is observed that scenario number 1, 2 and 3 tightly related with building the business community which are feeding to the other scenarios in the network. Scenario number 4 which is termed as knowledge sharing within the network has multidimensional objectives to establish smoother information among the scenario network.

The planning of business scenarios encourages organisational managers to envision plausible future prospects and consider how to take better opportunities and avoid potential threats or risks. It is considered as a strategic management tool for organisational managers for making strategic investment decisions under uncertainty. This tool involves scenario development, exposure identification, formulating customers' responses and implementation steps of integrated risk management process. During formulating scenarios planning, participant firms need to discuss current trends and future prospects arising in a firm's external environment. Through planning business scenario, the contingencies, uncertainties, trends and opportunities that are often unanticipated can be identified, evaluated and acted upon (Miller and Waller, 2003).

\section{Business partners and non-hierarchical collaboration}

Business partner can be defined as a commercial entity with which another commercial entity has some form or collaboration or alliance. It is driven by a clear understanding of mutual objectives and cooperative decision-making by multiple firms in order to continuous improvement of their performance (Bennett and Jayes, 1998). Partnering thus involves the major participants in an alliance that develops a cohesive environment enabling partners to openly interact and perform (Chen and Chen, 2007). Crowley and Karim (1995) proposed cooperative partnership using diagrams indicating permeable boundaries and indicating a cell-like organisation. They conceptualised that partnerships involved four dimensions:

1 adversarial (perceived by the involved parties as a win/lose situation and leading to more formal litigation)

2 guarded adversarial (relationships that strictly adhere to and are interpreted by the contracts)

3 informal partners (understand and cooperate with parties with fewer disputes)

4 project partners (equal partners working cooperatively to pursue a common set of goals).

In long term partnerships, there needs a commitment to exchange detailed and reliable information about product, capacity, demand and orders with customers and suppliers, improving planning and control processes and material flow and evolving to full collaboration within a network. A critical evaluation among partners are therefore required before proceed any kind s of collaboration with each other in order to achieve several business goals. Several important critical factors for partnerships are needed to be analysed to match the common requirements among partners. The selection process of business partners is not an easy task but a through understanding of the potential partners' business information is required. There is no formal process for selecting partners; however, predefined factors might be helpful to improve communication among potential 
partners. Firms usually select their partners through direct relationships, reputation and known experiences.

\subsection{Critical success factors of partnerships}

Strategic partnerships are increasingly gaining favour over go-it-alone strategies for firms to achieve fast and economical growth. It is becoming an increasingly common way for firms to the formation of partnerships to find and maintain competitive advantage. Business collaboration is perhaps on of the most innovative development in delivering a project efficiently. It provides a sound basis for achieving a win-win situation among partners. The fundamental principles of partnering, namely trust, commitment, communication, respect, and equality. It includes the appropriate consideration of the interest of all parties involves in the collaboration process at every level and aiming to build trust among the parties involved in a contract (Cowan et al., 1992; Uher, 1999).

Critical success factors of collaboration can be defined as those factors that determine the success or failure of a firm. These factors are measured by comparing the value of several predefined variables (noticed or unnoticed) in successful and unsuccessful partnerships. General measures of success in partnerships (satisfaction and sales volume in the relationship) can be stated as communication quality and participation, conflict resolution techniques, coordination and trust and a partnership attributes of commitment (Mohr and Spekman, 1994). Careful strategic planning and good collaborative attitudes are essential for its success, however the full benefits or values from collaboration has to be developed as it evolves (Hoffmann and Schlosser, 2001). The key success factors for collaborative business networks can be summarised as follows.

- development of trust between participants in the business community

- development of change management programs to reduce the natural reaction to change from internal personnel, at different levels of the organisation

- well defined, clear and formalised roles for all partner companies

- formalised and standard collaboration process

- availability of shared knowledge, competencies and experiences with partner companies

- human resources with the required technical skills and collaboration experience

- shared values between the companies in the business community

- enough financial resources for the defined strategic objectives

- the ICT support tools to be made availability to use by the companies at different levels involved.

The most significant factors as mentioned above are considered as the factors of high level for firms' management. There are even much more success factors for choosing a partner in lower level too. There needs to be special care before choosing for the success factors as the success or failure of any kind of collaboration mostly depends on the outcomes of the factors. These factors or variables might vary from one collaborative network to another network depending on the objectives and requirements. 


\subsection{Criterion for qualify a business partner}

The rapid growth of collaboration in recent years has been accompanied by high failure rates in the relationships. Significant care should be taken before initiating any kinds of collaboration or networking among potential partners. This collaboration can lead to premature termination because of higher cultural and corporate differences between partners. Right partner can increase the collaborative adaptability, improve the strategy-environment configuration and reduce uncertainty (Luo, 1997). There is relatively little empirical research has been reported in the literature, although the importance of selecting the right partner to the success of business networking has been widely stressed (Luo, 1997; Beamish, 1987).

Geringer (1991) proposed a twofold typology of partner selection criteria based on task related and partner related dimensions. Task related criteria are connected with operational skills and resources that a firm requires for its competitive success. Typical examples of task related criterions are patents, technical know-how, managerial experiences, financial resources and access to the market and distribution channels. On the other hand, partner related criteria refer to those factors that become relevant only if the chosen investment mode involves the presence of multiple partners. The examples of this type of criterions are the national or corporate culture of a partner, trust between the partners' management teams, and the degree of favourable past association between the partners and the size or corporate structure of the partner (Tatoglu, 2000). The generic requirements for qualifying for a potential partner can be summed up as follows.

- financial performance

- previous experience

- conflict of interest (competitor)

- trust between top management teams

- technical capabilities (know how)

- production capacity

- capability of electronically order processing

- $\quad$ growth rate (market access)

- economies of scale

- conform to host government policies

- $\quad$ environmental concern (green product)

- $\quad$ risk assessment

- health and safety

- $\quad$ event (abnormal situation) management capability.

Often the variables for selecting a partner are prioritised according to individual firm's requirements and strategies. These preferences are given in terms of relative importance of the variables or factors. It might be mentioned that the relative importance of the criterions would vary with nationality of foreign partner. In most literature, among the 
selection criterions trust between top management and the contribution of partner's resource are considered more important than others, although it varies from region to region globally (Hallen and Wiedersheim-Paul, 1979; Glaister, 1997).

\subsection{Assessment of a business partner}

There are many variables for assessing a business partner but the following four considers as the highly critical for any respect. The details of the four important criterions for assessing a partner are given as follows.

1 On time delivery (OTD): the business success and goodwill in any business highly depends on the record of the OTD of products or services. This critical success factor also categorised according to product types such as 'A type' product, 'B type' product, 'C type' product etc and individual delivery times are recorded separately. In this way, firms could prioritise their stream of products on the basis of customers' demand and revenue earnings.

2 Total lead time (TLT): TLT can be defined as the period between placement of an order and receipt of the ordered good(s). It starts when the order is received by the sales department and ends when the client pays the invoice. Reducing the lead-times is about speeding up information flows and changing the way processes work across and within companies. More often firms categorised their production line according to prioritised products such as 'Green line' for fastest product, 'Yellow line' for $2^{\text {nd }}$ fastest, 'Red line' for the slowest and so on.

3 Quality control: the issue of quality control affects highly on the assessment process of business collaboration. There are several factors could be identified to evaluate the quality of partner organisation. For instance, customers complain, packaging style or method, mal-working items, return of goods, documentation etc. It can be measured through first pass yield (FPY) methodology, where the numbers of defect items/products are expressed in percentage in order to visualise the quality concern. There are different standard methods available for firms to measure the quality of their products/services.

4 Business flexibility: business flexibility of a firm can be defined as the measurement of how easy it is to run a business by that specific firm. There are several ways to scale down this business flexibility. For instance, response time, replying the quotation, respect to the customer's needs, risk management etc. The flexibility in business environment is considered as an assessment tool for considering partnerships among firms.

\section{Empirical study: business cases}

At Net-Challenge project, the business cases represented three business fields: the textile and apparel, footwear and machine tools industries. In every business field, it was selected two case companies acting in the same network. The relation between the case companies in each business field was very close; the companies might be cross-owned or the supplier a spin-off from the main company. The selection to choose a combination like this was because of the confidentiality of part of the results. Since there are always 
two companies acting in the same network so most or even all of the confidential information can be exchanged, logged and analysed. The relations of these companies with their business partners was also analysed in order to deeply understand the present and potential future business networks these companies can promote.

\subsection{Textile and apparel industry}

The textile and apparel industry represents one of the largest industrial sectors of Portugal. The role of the textile industry is still very important for the country, though it has been decreasing - it employed around $4.3 \%$ of the labour force in $2006(23 \%$ in the manufacturing industry) and is responsible for $11.8 \%$ of the manufactured goods exported in 2006 and accounts for $2.0 \%$ of gross value added. The largest share of sales volume is with the European Union (EU) (around 75\% of business volume); exports to the USA have been decreasing and are now around 5\% of the total textile and apparel exports. The textile and apparel companies are located mostly in northern Portugal - Porto, Braga, Guimarães, Famalicão and Covilhã are the main centres. There are about 5,000 industrial companies producing in all sub-sectors of textiles and apparel, some of them vertically integrated, and the vast majority $(90 \%)$ are small and micro companies, most of them employing less than ten people. The management lacks technical expertise.

The sector used to be characterised by low technological content and intensive labour processes, particularly in clothes manufacturing, with the use of an outsourced workforce and a reduction of employment and investment, but the situation has been changing. Together with a large number of bankruptcies, the sector has been moving towards higher added value products, superior service level, short lead-times, and competence in product development, production flexibility and higher technological content, in order to compete on a global scale. Investment in equipment has increased and there has also been investment in training and residual investment in R\&D. It is possible to identify two types of companies in Portugal: one type with some internationalisation capacity, with its own labels, adding a higher value to the product, with some R\&D capacity, controlling the whole productive process; and a second type totally concentrating on the production of clothes for other companies without any other function, having little added value and almost no products or process development. A third in-between type could be characterised by product design capacity but producing for large distributors and known designers.

\subsection{Footwear industry}

The footwear sector is a diversified industry which covers a wide variety of materials (textile, plastics, rubber and leather) and products from different types of men's, women's and children's footwear to more specialised products like snowboard boots and protective footwear. This diversity of end products corresponds to a multitude of industrial processes, enterprises and market structures. The European footwear industry is highly competitive, both in the EU's internal market, and in global markets, mostly due to its quality, design and fashion attributes. However, the trade deficit in the footwear sector has more than doubled in five years to $€ 7.0$ billion in 2007 . Reasons contributing to this large trade deficit are the growing difficulties of EU industries in competing with countries with low labour costs and less regulation, and the strength of the Euro. 
In fact, European footwear production has decreased from 706.704 .000 pairs in 2005 to 642.386 .000 pairs in 2007, while imports have grown from 1.932 .645 pairs in 2005 to 2.433 .522 .000 pairs in $2008(+25,9 \%)$ and exports in the same period have increased only by $9,7 \%$, moving from 161.914 .000 to 177.691 .000 . In 2006, the footwear sector included 26,600 enterprises, generating $€ 26.2$ billion in turnover and $€ 6.9$ billion in added value $(0.5 \%$ of total EU manufacturing), and directly employed 388,000 people. Two thirds of the total EU footwear production is actually concentrated in three countries: Italy, Spain and Portugal, with Italy producing around $50 \%$ of EU production. The main suppliers of footwear to the EU are China and Vietnam, which together account for more than $60 \%$ of footwear imports into the EU (in value). Moreover, imports from China have grown by around $21 \%$ from 2005 to 2008, and higher increases (more than 35\%) have been achieved by other important suppliers such as India and Indonesia.

The European footwear industry consists of a large number of small and medium sized enterprises, most of which are grouped in regions with a high level of industrial homogeneity. However, there are variations between different member states: French and German businesses employ on average about 100 workers, while Spanish and Italian ones often no more than 20 workers. The other member states lie between these two extremes. This structure can be considered as both a strength and a weakness, as SMEs are generally more flexible, and yet at the same time more likely to lack investment capability. At present, the footwear industry is also highly globalised. Competition from countries with low labour costs and less-regulated working conditions has forced EU footwear production into serious restructuring strategies and re-location policies. The overall performance of footwear in the EU has been deeply affected by this unbalanced supply to the global market.

\subsection{Machine tools industry}

The machine tool industry is a very traditional and mature industrial sector, widely spread in northern Spain, with a very long tradition in the Basque Country region, undoubtedly the largest industrial zone of Spain. Although northern Spanish industry is nowadays more diversified, the machine tool industry still makes up a large part of the economy of the northern zone. More than $60 \%$ of the industrial production of some regions in the Basque Country has in the past decades been related in some way to machine tools; we are of course not only talking about industrial companies at the end of the supply chain - designing, building and selling machine tools, but also all the small SMEs building different components and accessories involved in the complex machine tool manufacturing process.

Nowadays other types of industrial activities have gained more presence and turnover, but nevertheless, the machine tool industry still has an important percentage of all the industrial activity of the north of Spain, around $40 \%$. This is because the machine tool industry has been for many years a fundamental supplier of other industrial activities such as the automotive, railway, renewable energy and aeronautics industries, actively participating in several phases of the supply chain of these bigger industries. The situation has dramatically worsened in the past two years, and many machine tool companies are undergoing a critical period, unable to cope with the economic and social problems that have appeared. Many of them have laid-off workers and some of the small SMEs have closed completely. Companies that have more or less overcome the situation know that reducing costs is not the only way to compete with the emerging economies; 
they know they must focus their effort on achieving more innovative products and services, at least different from what they have been for many years and are currently offering.

\subsection{Summary of the case industries}

The brief summary of the above mentioned six case industries are summarised in Table 2 in respect to country, business field, number of employees and annual turnover.

Table 2 Business information of the six case industries

\begin{tabular}{lcccc}
\hline Company & Country & Business field & Number of employees & Turnover \\
\hline Case A & Portugal & Textile and apparel & 800 & $50 \mathrm{M} €$ \\
Case B & Portugal & Textile and apparel & 23 & $5 \mathrm{M} €$ \\
Case C & Italy & Footwear & 10 & $0.5 \mathrm{M} €$ \\
Case D & Italy & Footwear & 35 & $8.5 \mathrm{M} €$ \\
Case E & Spain & Machine tool & 6 & $1.8 \mathrm{M} €$ \\
Case F & Spain & Machine tool & 150 & $23 \mathrm{M} €$ \\
\hline
\end{tabular}

\section{Discussion and conclusions}

The establishment of business relationships and collaborations is becoming increasingly important in the era of economical globalisation. Global companies are moving from their traditional supply base business strategy towards much more focusing on corporate partnerships. This partnership provides the opportunity to combine their partners' capacities and capabilities for achieving definite business opportunities, which may not be possible by staying isolation. Before formation of any forms of collaborative environment (hierarchical or non-hierarchical, shorter term or longer trem) among companies, it is needed to identify the possible partners (e.g., clients or suppliers), providing them with accurate information, establishing a common communication infrastructure and starting collaborative operational activities (design and engineering, quotation preparation, aggregate and detailed planning, scheduling, etc).

The formation of dynamic and non-hierarchical business networks among SMEs for complex product design and manufacturing is considered as the key for their business sustainability. Temporary networks or virtual enterprises become a solution for emerging market opportunities. However, there is a lack of proper network management methodologies and ICT standard for communications among companies. Recent development in technology, including the rapid increase of the use of the internet supports efficient and cost-effective communication among collaborative SMEs. This efficient communication pattern among SME partners contributes to reduce lead times and increase market responsiveness.

Before exploiting any benefits from business collaboration, it is crucial to collect the essential business scenarios and requirements from the participating companies. Proper methodological support is also necessary to collect such business scenarios and requirements. This research provides a step by step methodology to perform such activities extensively and efficiently. This research provides the general outline of 
Net-Challenge methodology to establish a virtual organisation successfully. The outcomes from the EU project, Net-Challenge are provided in this research to motivate companies especially SMEs to be collaborative and enjoying business successful opportunities. The critical success factors for partnership, criterions for qualifying a business partner and assessment of a partner are presented in this research with the objective to form non-hierarchical business collaboration. The empirical study considering the brief outlines of the three case networks (consisting of six case industries) are also briefly elaborated within the scope of this paper.

\section{Acknowledgements}

The authors would like to acknowledge the co-funding of the European Commission in NMP priority of the Seventh RTD Framework Programme (2007-13) for the Net Challenge project (Innovative Networks of SMEs for Complex Products Manufacturing), Ref. CP-FP 229287-2. The authors also acknowledge the valuable collaboration provided by the project team during the research work.

\section{References}

Ahern, R. (1993) 'Implications of strategic alliances for small R\&D intensive firms', Environment and Planning, Vol. 25, No. 10, pp.1511-1526.

Almeida, R., Carneiro, L., Kankaanpää, T., Rymaszewska, A., Loichate, M., Mancisidor, L., Fornasiero, R. and Chiodi, A. (2010) 'Methodology V1', Delivery D1.4, Net-Challenge Project, EU project, Ref: CP-FP 229287-2.

Beamish, P.W. (1987) 'Joint ventures in less developed countries: partner selection and performance', Management International Review, Vol. 27, No. 1, pp.23-37.

Bennett, J. and Jayes, S. (1998) The Seven Pillars of Partnering: A Guide To Second Generation Partnering, Thomas Telford: UK.

Bititci, U.S., Martinez, V., Albores, P. and Parung, J. (2004) 'Creating and managing value in collaborative networks', International Journal of Physical Distribution \& Logistics Management, Vol. 34, Nos. 3/4, pp.251-268.

Camarinha-Matos, L.M. and Afsarmanesh, H. (2007) 'Classes of collaborative networks', in Putnik, G. and Cunha, M.M. (Eds.): Encyclopedia of Networked and Virtual Organizations, Idea Group.

Camarinha-Matos, L.M., Afsarmanesh, H. and Ollus, M. (2008) 'Ecolead and CNO base concepts', in Camarinha-Matos, L.M., Afsarmanesh, H. and Ollus, M. (Eds.): Methods and Tools for Collaborative Networked Organizations, Springer Science+Business Media, LLC.

Chen, W.T. and Chen, T.T. (2007) 'Critical success factors for construction partnering in Taiwan', International Journal of Project Management, Vol. 25, No. 5, pp.475-484.

Cowan, C., Gray, C. and Larsen, E. (1992) 'Project partnering', Project Management Journal, Vol. 22, pp.5-12.

Crowley, L.G. and Karim, A. (1995) 'Conceptual model of partnering', Journal of Management in Engineering, Vol. 11, No. 5, pp.33-39.

Geringer, J.M. (1991) 'Strategic determinants of partner selection criteria in international joint ventures', Journal of International Business Studies, Vol. 22, No. 1, pp.41-61.

Glaister, K.W. (1997) 'Strategic motives and selection criteria in international joint ventures: perspectives of UK firms and foreign firms', 24th Annual Conference of Academy of International Business, Vol. 2, pp.87-108, Leeds University Business School. 
Hallen, L. and Wiedersheim-Paul, F. (1979) 'Psychic distance and buyer-seller interaction', in Buckley, P.J. and Ghauri, P.N. (Eds.): Organisaijon, Marknad och Samhalle, Vol. 16, pp.308-324, Dryden Press, London.

Hoffmann, W.H. and Schlosser, R. (2001) 'Success factors of strategic alliances in small and medium-sized enterprises - an empirical survey', Long Range Planning, Vol. 34, No. 3, pp.357-381.

Jarke, M., Bui, T.B. and Carroll, J.M. (1998) 'Scenario management: an interdisciplinary approach', Requirements Engineering, Vol. 3, Nos. 3-4, pp.155-173.

Jones, T. and Bowie, N. (1998) 'Moral hazards on the road to the 'virtual' corporation', Business Ethics Quarterly, Vol. 8, No. 2, pp.273-292.

Levy, M., Loebbecke, C. and Powell, P. (2003) 'SMEs, co-opetition and knowledge sharing: the role of information systems', European Journal of Information Systems, Vol. 12, No. 1, pp.3-17.

Luo, Y. (1997) 'Partner selection and venturing success: the case of joint ventures with firms in the people's republic of China', Organizational Science, Vol. 8, No. 6, pp.648-862.

Miller, K.D. and Waller, H.G. (2003) 'Scenarios, real options and integrated risk management', Long Range Planning, Vol. 36, No. 1, pp.93-107.

Mohr, J. and Spekman, R. (1994) 'Characteristics of partnership success: partnership attributes, communication behavior, and conflict resolution techniques', Strategic Management Journal, Vol. 15, No. 2, pp.135-152.

Mytelka, L. (1991) 'Crisis, technological change and the strategic alliance', in Mytelka, L. (Ed.): Strategic Partnerships and the World Economy, pp.7-34, Pinter, London.

Narula, R. (2004) 'R\&D collaboration by SMEs: new opportunities and limitations in the face of globalisation', Technovation, Vol. 24, No. 2, pp.153-161.

Nooteboom, B. (1994) 'Innovation and diffusion in small firms: theory and evidence', Small Business Economics, Vol. 6, No. 5, pp.327-347.

Ratnasingam, P. (2001) 'Inter-organizational trust in EDI adoption', Internet Research: Electronic Networking Applications and Policy, Vol. 11, No. 1, pp.261-268.

Robson, P.J.A. and Bennett, R.J. (2000) 'SME growth: the relationship with business advice and external collaboration', Small Business Economics, Vol. 15, No. 3, pp.193-208.

Rothwell, R. and Dodgson, M. (1994) 'Innovation and size of firm', in Dodgson, M. (Ed.): Handbook of Industrial Innovation, pp.310-324, Edward Elgar, Aldershot.

Schoemaker, P.J.H. (1993) 'Multiple scenario development: its conceptual and behavioral foundation', Strategic Management Journal, Vol. 14, No. 3, pp.193-213.

Singh, K. and Mitchell, W. (1996) 'Precarious collaboration: business survival after partners shut down or form new partnerships', Strategic Management Journal, Vol. 17, No. 7, pp.99-115.

Tatoglu, E. (2000) 'Western joint ventures in turkey: strategic motives and partner selection criteria', European Business Review, Vol. 12, No. 3, pp.137-147.

Uher, E.T. (1999) 'Partnering performance in Australia', Journal of Construction Procure, Vol. 5, No. 2, pp.163-176.

Van Dijk, B., den Hertog, R., Menkveld, B. and Thurk, R. (1997) 'Some new evidence on the determinants of large- and small-firm innovation', Small Business Economic, Vol. 9, No. 4, pp.335-343.

Webster, J. (1995) 'Networks of collaboration or conflict? Electronic data interchange and power in the supply chain', The Journal of Strategic Information Systems, Vol. 4, No. 1, pp.31-42.

Welty, B. and Becerra-Fernandez, I. (2001) 'Managing trust and commitment in collaborative supply chain relationships', Communications of the ACM, Vol. 44, No. 3, pp.67-73. 